\title{
Perception of Tourists Regarding the Smoke-Free Policy at Suvarnabhumi International Airport, Bangkok, Thailand
}

\section{Nithat Sirichotiratana ${ }^{1, \dagger}$, Subash Yogi ${ }^{2, \dagger}$ and Chardsumon Prutipinyo ${ }^{3, \dagger, *}$}

1 Health Administration Department, Faculty of Public Health, Mahidol University, 420/1 Rajvithi Road, Rajthevi District, Bangkok 10400, Thailand; E-Mail: nithats@gmail.com

2 Saath-Saath Project, FHI360, GPO Box 8803, Gopal Bhawan, Anamika Galli Baluwatar, Kathmandu, Nepal; E-Mail: subash.yogi@gmail.com

3 Health Administration Department, Faculty of Public Health, Mahidol University, 420/1 Rajvithi Road, Rajthevi District, Bangkok 10400, Thailand

$\dagger$ These authors contributed equally to this work.

* Author to whom correspondence should be addressed; E-Mail: chardsumon.pru@mahidol.ac.th or chardsumon@gmail.com; Tel.: +662-644-8833 (ext. 116); Fax: +662-644-8833 (ext. 193).

Received: 11 June 2013; in revised form: 13 August 2013 / Accepted: 15 August 2013 /

Published: 30 August 2013

\begin{abstract}
This study was conducted during February-March 2012 to determine the perception and support regarding smoke-free policy among tourists at Suvarnabhumi International Airport, Bangkok, Thailand. In this cross-sectional study, 200 tourists $(n=200)$ were enrolled by convenience sampling and interviewed by structured questionnaire. Descriptive statistics, chi-square, and multinomial logistic regression were adopted in the study. Results revealed that half $(50 \%)$ of the tourists were current smokers and 55\% had visited Thailand twice or more. Three quarter (76\%) of tourists indicated that they would visit Thailand again even if it had a $100 \%$ smoke-free regulation. Almost all ( $99 \%$ ) of the tourists had supported for the smoke-free policy (partial ban and total ban), and current smokers had higher percentage of support than non-smokers. Two factors, current smoking status and knowledge level, were significantly associated with perception level. After analysis with Multinomial Logistic Regression, it was found that perception, country group, and presence of designated smoking room (DSR) were associated with smoke-free policy. Recommendation is that, at institution level effective monitoring system
\end{abstract}


is needed at the airport. At policy level, the recommendation is that effective comprehensive policy needed to be emphasized to ensure smoke-free airport environment.

Keywords: tourists; smoke-free policy; smoke-free airport; perception; Thailand

\section{Introduction}

Tobacco continues to be the leading global cause of preventable deaths. It is classified as a "known human carcinogen" (cancer-causing agent) by the US Environmental Protection Agency (EPA). Second hand smoke (SHS) also called environmental tobacco smoke, involuntary smoke, and passive smoke, is the combination of "sidestream" and "mainstream" smoke. It is also known to be a human carcinogen [1]. Around the world, an estimated 33\% male and 35\% female non-smokers are regularly exposed to SHS [2] at home and workplaces. Studies have clearly shown nonsmokers risk of developing lung cancer by $20-30 \%$ at work place or at home from exposure to SHS [3].

In 2007 smoke-free policy guidelines under article 8 of World Health Organization Framework Convention on Tobacco Control (WHO FCTC) were formed and were unanimously agreed as the safest policy against SHS [4]. Finally the convention concluded that by going $100 \%$ smoke-free and not permitting enclosed or substantially enclosed workplaces, public places, public transport, international airports and bars and restaurants can protect the health of non-smokers and smokers [5].

It has been seen that low and middle-income countries are effectively implementing smoke-free legislation, such as Kenya, Niger, Panama and Thailand [6]. Asian and developing countries harbor $70 \%$ of the world's 1.1 billion smokers [7]. In China seven of 10 non-smoker adults are exposed to SHS [8], while Indonesia has not yet implemented the smoke-free policy as outlined by the FCTC article 8 [9]. Protecting people from SHS particularly in the indoor places such as airports, bars, and restaurants is a pivotal issue.

Some Southeast Asian countries have strong laws that offer a high standard of protection for people. However these laws do not comply with the maximum standards set forth by the FCTC since they allow Designated Smoking Rooms (DSRs). Thailand and Singapore, being the tobacco control leaders in the region, are still unable to eliminate DSRs.

A Hong Kong technical feasibility study of smoking concluded that even the best designed designated smoking rooms do not fully protect non-smokers from secondhand smoke. Some leakage of secondhand smoke is inevitable. The study also found that smoking rooms were not practical due to the technical demands and costs associated with the building, operation and maintenance of the rooms [10]. In Santiago, Chile, one study found that smoke from designated smoking rooms leaked into non-smoking areas. Non-smoking areas of venues that allowed smoking in ventilated designated smoking rooms had nicotine concentration in the air 3.2 times higher than completely smoke-free venues [11]. Recent studies document that toxins from tobacco smoke remain even after the cigarette has been extinguished; this is known as 'third-hand' smoke. As a result, indoor spaces become contaminated with tobacco toxins even after the visible smoke disappears [12].

A World Bank report on the global tobacco epidemic concluded that smoking restrictions can reduce overall tobacco consumption by $4-10 \%$ [13]. The United States Occupational Health and 
Safety Administration reported that the National Energy Management Institute estimated that clean air increases productivity by $3.5 \%$ or $15 \mathrm{~min}$ per day for employees, while 94 state government office buildings surveyed indicated that poor indoor air quality attributed to $14 \mathrm{~min}$ per day productivity loss or $3 \%$ [14]. Comprehensive smoke-free laws, or total ban on indoor smoking, will fully protect non-smokers from secondhand smoke exposure, and the only effective way to ensure that exposure will not occur [3].

Designated smoking rooms at the airports are to facilitate the passenger and minimize the harms from SHS but studies at airport with well-functioning designated smoking rooms in United States found evidence of secondhand smoke leakage to the indoor smoke-free areas due to the opening and closing of doors [13]. Another study in U.S done in airports as well have shown that millions of passengers and thousands of airport workers are still being needlessly exposed to serious health hazards because of the ongoing indoor smoking in a handful of major hub airports [15].

The airports are allowing ventilation systems which do not eliminate the hazard of second-hand smoke. Studies have shown that nicotine concentrations adjacent to outdoor smoking areas at airports can be as high as those in some smokers' homes [16]. The study carried out at the airport shows that airport smoking rooms expose non-smokers in adjacent non-smoking areas to a significant concentration of nicotine vapor from SHS [17].

Thus, by adopting 100\% smoke-free indoor air policies, airports can choose to save money, space, and most importantly, people's lives - both airport employees and passengers/travelers. Gap in the law means patrons and workers still have smoke blown in their faces at workplaces and public places. These unequal protections from exposure to SHS leaves everyone at the risk of life threatening public health effects relate to heart attack, cancer and direct health costs [18]. Thus, this study, by finding out the knowledge and perception of the tourists on smoke-free policy at the airport along with their support for the $100 \%$ smoke-free law, would be helpful in advocating the airport for total smoking ban; ultimately saving lives rather than killing people by allowing ventilation rooms inside the airport.

\section{Experimental Section}

\subsection{Research Design}

A cross-sectional study was conducted to explore the knowledge, perception and support on smoke-free airport policy among the tourists at Suvarnabhumi International Airport, about $25 \mathrm{~km}$ east of Bangkok. In the study quantitative methods and tools were used to gather the information in order to quantify the variables under the study.

The target population for the study were the tourist passengers, i.e., non-Thai, above 18 years of age. Since the number of tourists passing through the airport was dynamic, the sample size depended on the season and time of the day. Therefore, researchers employed an incidental (purposive) sampling method among departing tourists to be included in this pilot study. For calculating the sample size in this study was conducted in order to estimate the prevalence of perception on smoke-free policy which was found to be 0.86 . Thus at $95 \%$ CI with $5 \%$ level of significance sample size of 180 was determined for the study. 
Also another method was used to get to the conclusion. By projecting a high rejection rates during the interview process, an additional 20 samples had been taken as precaution for error from data collection. Thus, 200 incidental samples were collected for the study.

\subsection{Research Instruments}

A structured questionnaire were used to obtain the information on knowledge, perception and support on smoke-free policy from the tourists through interview. The questionnaire was constructed based on a social science research method with measurement on a Likert scale with 5 levels: "Strongly Disagree", "Somewhat Disagree", "Neutral", "Somewhat Agree", and "Strongly Agree". "Strongly Disagree" equals to 1, while "Strongly Agree" equals to 5. The structured questionnaire had closed ended, multiple response and multiple choice questions. The questionnaires were divided into three sections. The questionnaire was pre-tested among 30 international students for clarity, validity and reliability. Furthermore, questions were reviewed by tobacco control literature and experts. Finally, consensus on the tools for measuring the research objectives was reached by close consultation with experts. For measuring the perception, all 8 items from questionnaire were computed as a whole. After the scales of these eight items were computed, we tested for reliability. Cronbach's alpha coefficient of 0.81 was obtained.

\subsection{Data Collection}

Prior to the data collection, permission from the related authorities were obtained and ensured. The researcher along with an assistant collected the data at the airport from the tourists. During the data collection researcher first provided the information sheets and explained the objectives and procedure of data collection to the respondents, and obtained verbal and written informed consent voluntarily prior to the interview. The researchers received approval from Ethical Review Committee for Human Research, Faculty of Public Health, Mahidol University, certificate of approval number MUPH 2012-031.

\subsection{Data Analysis}

For data analysis, computerized statistical software for data analysis were used. Descriptive statistics included frequency, percentage, mean and standard deviation. These were applied for describing characteristics of samples, knowledge and perception levels. Data were presented in terms of percentage, mean and standard deviation as per descriptive analysis. Chi-Square, Multinomial Logistic Regression analysis were used for testing association with support for the $100 \%$ smoke-free policy. 


\section{Results and Discussion}

\subsection{Findings from Descriptive Statistics}

\subsubsection{General Characteristics of the Respondents}

Table 1 below describes the general characteristics of the 200 respondents. The distribution of the general characteristics like age, sex, education, marital status and smoking status are mentioned in the table. The table also provides information on the number of visits made to Thailand by the tourists and the geographical region they belong to, i.e., residence of the respondents. In addition, their views on coming to Thailand when it goes $100 \%$ smoke-free were also described in the table.

Exploration at the smoking status of the respondents, surprisingly revealed that exactly half of the respondents taken in the study were currently smokers where as $40 \%$ had never smoked and $10 \%$ had given up smoking. Similarly, it was also found that $45.1 \%$ respondents were on their first visit to Thailand and $29 \%$ had visited over three times. Likewise on analyzing the respondents' opinion on coming to Thailand when it goes $100 \%$ smoke-free; two-third $(65.8 \%)$ of the respondents replied that they would like to come to Thailand, whereas $12 \%$ were of the opposite view and the rest were unsure.

Table 1. General Characteristics of Respondents.

\begin{tabular}{|c|c|c|}
\hline Variables & Number & Percent \\
\hline \multicolumn{3}{|l|}{ Age Group/years $(n=199)$} \\
\hline $18-35$ & 114 & 57.0 \\
\hline $35+$ & 86 & 43.0 \\
\hline \multicolumn{3}{|l|}{$\operatorname{Sex}(n=200)$} \\
\hline Male & 126 & 63.0 \\
\hline Female & 74 & 37.0 \\
\hline \multicolumn{3}{|l|}{ Respondents Residence * $(n=193)$} \\
\hline Africa & 4 & 2.1 \\
\hline The Americas & 21 & 10.9 \\
\hline South-East Asia & 14 & 7.3 \\
\hline Europe & 127 & 65.8 \\
\hline Eastern Mediterranean & 8 & 4.1 \\
\hline Western Pacific & 19 & 9.8 \\
\hline \multicolumn{3}{|l|}{ Educational Status $(n=195)$} \\
\hline Secondary or lower & 9 & 4.6 \\
\hline High School & 57 & 29.2 \\
\hline University & 129 & 66.2 \\
\hline \multicolumn{3}{|l|}{ Marital Status $(n=197)$} \\
\hline Single/In Relationship & 77 & 39.1 \\
\hline Married & 108 & 54.8 \\
\hline Divorced/Widow(er) & 12 & 6.1 \\
\hline \multicolumn{3}{|l|}{ Smoking Status $(n=200)$} \\
\hline Current Smoker & 100 & 50.0 \\
\hline Ex-smoker & 20 & 10.0 \\
\hline Non-Smoker & 80 & 40.0 \\
\hline \multicolumn{3}{|l|}{ Number of visit to Thailand $(n=193)$} \\
\hline First time & 87 & 45.1 \\
\hline 2-3 Times & 50 & 25.9 \\
\hline More than 3 times & 56 & 29.0 \\
\hline
\end{tabular}


Table 1. Cont.

\begin{tabular}{ccc}
\hline Variables & Number & Percent \\
\hline Respondents Views on coming to Thailand during & $\mathbf{1 0 0 \%}$ SMF $* *$ & $(\boldsymbol{n}=\mathbf{1 9 9})$ \\
\hline Yes & 131 & 65.8 \\
Might & 21 & 10.6 \\
Not Sure & 23 & 11.6 \\
No & 24 & 12.0 \\
\hline
\end{tabular}

* 43 countries respondents taken in the study classified into WHO six regions and ** SMF $=$ Smoke-free Environment.

\subsubsection{Perception of the Respondents on Airport Smoke-Free Policy}

For measuring the perception, all eight items from questionnaire were computed as a whole. The eight items were as follows: 1 . Smoking inside the airport affects the health of both the passengers and workers at the airport. 2. Airports should have a 100\% smoke-free environment. 3. A smoking ban would be unfair to smokers. 4. Smoking in the ventilated room does not eliminate the hazards of second hand smoking in the airport. 5. A smoke-free policy is difficult to enforce. 6. Majority of population support smoke-free airport policy. 7. Smoke-free policy is a better method to help smokers to quit smoking. 8. I support smoke-free airports. The 5 levels of perception was further reduced to 3 levels in order to categorized into "Poor", "Average", "Good". The findings on perception of the tourists on airport smoke-free policy showed that males had better perception than females in all three categories of "Poor". "Average", and "Good", as shown in Table 2 below.

Table 2. Tourist's perception levels on airport smoke-free policy by sex.

\begin{tabular}{ccccc}
\hline & \multicolumn{2}{c}{ Categories of perception (Levels) } & \multirow{2}{*}{ Total (\%) } \\
\cline { 2 - 4 } & Poor (\%) & Average (\%) & Good (\%) & \\
\hline Male & 19 & 49 & 58 & 126 \\
& $(15.1)$ & $(38.9)$ & $(46.0)$ & $(100.0)$ \\
Female & 16 & 32 & 26 & 74 \\
& $(21.6)$ & $(43.2)$ & $(35.1)$ & $(100.0)$ \\
& 35 & 81 & 84 & 200 \\
& $(17.5)$ & $(40.5)$ & $(42.0)$ & $(100.0)$ \\
\hline
\end{tabular}

\subsubsection{Respondents Support for Smoke-Free Policy}

When asked regarding their support for smoke-free policies at the airport in the study, it was found that males support 'Total Ban' more than females, while females support "Partial Ban" more than males, as shown in Table 3.

Table 3. Support for smoke-free policies among the respondents by sex.

\begin{tabular}{ccccc}
\hline \multirow{2}{*}{ Sex } & \multicolumn{2}{c}{ Choice for smoke-free policy at the airport among the respondents } & \multirow{2}{*}{ Total (\%) } \\
\cline { 2 - 4 } & No Ban (\%) & Partial Ban (\%) & Total Ban (\%) & $125(100.0)$ \\
Male & $3(2.4)$ & $58(46.4)$ & $64(51.2)$ & $29(39.2)$ \\
Female & $0(0.0)$ & $45(60.8)$ & $93(46.7)$ & $74(100.0)$ \\
Total & $3(1.5)$ & $103(51.8)$ & & $199(100.0)$ \\
\hline
\end{tabular}




\subsection{Findings from Inferential Statistics}

To explore the associations and relationships among the dependent and independent variables, Chi-square test, Fisher Exact test, one way ANOVA analysis and bivariate logistic regression analysis were adopted. Based on these analyses this section describes the association and relationships between the variables.

3.2.1. Association between General Characteristics and Perception on Smoke-Free Policy (Chi-Square Test Statistics)

The number, percentage and Chi-square values obtained from the findings are listed in Table 4 below. The table clearly shows that no statistically significant association existed between the general characteristic variable and level of perception, except for current smoking status of the respondents, at 5\% level of significance with p-value less than 0.001 and chi-square value 19.568 at $\mathrm{df}=2$.

Table 4. Association between general characteristics and perception on smoke-free policy.

\begin{tabular}{|c|c|c|c|c|c|}
\hline \multirow{2}{*}{ General Characteristics } & \multirow{2}{*}{ Total $(n)$} & \multicolumn{3}{|c|}{ Levels of Perception (\%) } & \multirow{2}{*}{$\chi^{2}$} \\
\hline & & Poor Number & Fair Number & Good & \\
\hline Age Group (years) & 200 & & & & \\
\hline $18-35$ & 114 & $21(18.4)$ & $51(44.7)$ & $42(36.8)$ & 2.983 \\
\hline $35+$ & 86 & $14(16.3)$ & $30(34.8)$ & $42(48.8)$ & \\
\hline Sex: Male & 126 & $19(15.1)$ & $49(38.8)$ & $58(46.0)$ & 2.676 \\
\hline Female & 74 & $16(21.6)$ & $32(43.2)$ & $26(35.1)$ & \\
\hline Educational Status & 195 & & & & \\
\hline Up to High School & 66 & $14(21.2)$ & $25(37.9)$ & $27(40.9)$ & 2.312 \\
\hline University & 129 & $21(16.3)$ & $54(41.9)$ & $54(41.9)$ & \\
\hline Marital Status & 198 & & & & \\
\hline Single/In Relationship & 108 & $22(20.4)$ & $47(43.5)$ & $39(36.1)$ & 7.691 \\
\hline Married & 77 & $9(11.7)$ & $30(39.0)$ & $38(49.4)$ & \\
\hline Divorced/Widow(er) & 12 & $4(33.3)$ & $2(16.7)$ & $6(50.0)$ & \\
\hline Current smoking Status & 200 & & & & \\
\hline Non-Smoker & 100 & $28(28.0)$ & $42(42.0)$ & $30(30.0)$ & $19.568 * *$ \\
\hline Smoker & 100 & $7(7.0)$ & $39(39.0)$ & $54(54.0)$ & \\
\hline No. of visit to Thailand & 193 & & & & \\
\hline First time & 87 & $13(14.9)$ & $40(46.0)$ & $34(39.1)$ & 8.982 \\
\hline 2-3 Times & 50 & $6(12.0)$ & $23(46.0)$ & $21(42.0)$ & \\
\hline More than 3 times & 56 & $15(26.8)$ & $14(25.0)$ & $27(48.2)$ & \\
\hline Knowledge levels & 200 & & & & \\
\hline Poor & 147 & $16(10.9)$ & $57(38.8)$ & $74(50.3)$ & $24.152 * *$ \\
\hline Average & 35 & $12(34.3)$ & $15(42.9)$ & $8(14.7)$ & \\
\hline Good & 18 & $7(38.9)$ & $9(50.0)$ & $2(11.1)$ & \\
\hline
\end{tabular}




\subsubsection{Support for $100 \%$ Smoke-Free Policy}

In studying factors associating with the smoke-free policy, results from multinomial logistic regression (Table 5) indicate that there are three dependent variables which associate with support for a $100 \%$ smoke-free policy, with statistical significance at $p$-value $=0.05$. They are tourists' level of perception, region of respondent residence, and presence of Designated Smoking Room (DSR).

Comparing 'average' category group as level of perception, with reference category group of 'poor', results indicates that the likelihood for support for a $100 \%$ smoke-free policy is 13.324 . Comparing the 'good' category group as level of perception, with reference to the category group of 'poor', the results indicate that likelihood of support for a $100 \%$ smoke-free policy is 3.854 . Respondents with good perception had a better support for the policy, which is statistically significant.

Comparing the region of respondent residence with reference region of Africa, the likelihood of support for a $100 \%$ smoke-free policy is 8.334 . If comparing European region of residence to the reference region of Africa, the likelihood of support for a $100 \%$ smoke-free policy is 7.514 . If DSR is present at the airport, the likelihood of support for a $100 \%$ smoke-free policy is 0.254 (Table A4 in Appendix section).

Table 5. Likelihood Ratio Tests.

\begin{tabular}{lcccc}
\hline \multirow{2}{*}{ Effect } & \multicolumn{2}{c}{ Model Fitting Criteria } & \multicolumn{2}{c}{ Likelihood Ratio Tests } \\
\cline { 2 - 5 } & $\begin{array}{c}-\mathbf{2} \text { Log Likelihood of } \\
\text { Reduced Model }\end{array}$ & Chi-Square & df & Sig. \\
\hline Intercept & $137.025^{\text {a }}$ & 0.000 & 0 & \\
SEX & 137.156 & 0.131 & 1 & 0.717 \\
MRTL_STAT & 138.323 & 1.298 & 1 & 0.255 \\
Knowledge_level & 137.767 & 0.742 & 2 & 0.690 \\
Age_group & 138.741 & 1.715 & 1 & 0.190 \\
Level_Perception & 152.628 & 15.603 & 2 & 0.000 \\
Country_Group & 156.317 & 19.292 & 5 & 0.002 \\
Come_again, Opinion on visiting Thailand & 141.849 & 4.824 & 2 & 0.090 \\
Awareness on smoke-free & 138.353 & 1.328 & 1 & 0.249 \\
Fine for violating the policy & 137.987 & 0.962 & 1 & 0.327 \\
Pressence of DSRs & 141.218 & 4.192 & 1 & 0.041 \\
\hline
\end{tabular}

The chi-square statistic is the difference in -2 log-likelihoods between the final model and a reduced model. The reduced model is formed by omitting an effect from the final model. The null hypothesis is that all parameters of that effect are 0 ; ${ }^{\text {a }}$ This reduced model is equivalent to the final model because omitting the effect does not increase the degrees of freedom.

\section{Discussion}

Different studies have been done in restaurants, bars and hotel lobbies. The purpose of this study was to determine the perception and support of the tourists regarding smoke-free policy at Suvarnabhumi International Airport, Bangkok, Thailand. In this study the findings showed that current smoking status, knowledge of airport smoke-free policy, respondents residence (WHO regions) were significantly associated with their perception of the smoke-free policy at the airport. Also, existing 
knowledge, awareness statements about airport smoking and smoking places, fine for flouting the law and presence of DSRs were significantly associated with their support for a 100\% smoke-free policy. It was also found that smokers had better knowledge and better perception of smoke-free policy at the airport than non-smokers. Respondents from the Eastern Mediterranean and South-East Asia regions, with poor perception of the policy, had a better support for the $100 \%$ smoke-free policy.

This was a pilot study, which had weakness in that the sample was non-randomized, but rather was an incidental sample. This study was conducted among a transient tourist population, which depended on seasonal and timing of traveling. Therefore, it was not possible to control for bias. However, researchers were trying to control bias by exploring data distribution and normality.

The findings from this study may be used to better understanding perceptions on the policy which can either encourage or discourage smoke-free policy and it is critical to help inform and consolidate tobacco control policy. It could help policy makers and implementers to plan and design programmes towards enhancing awareness through education, advocacy and better enforcement of the policy. This results and recommendations will provide the outline of changes that needs to be brought about the existing policy at the airport and ultimately can contribute in initiating the foundation towards effective comprehensive policy at the airport.

\subsection{General Characteristics}

Most respondents surveyed were middle aged adults (aged 18-35 years) and more than half of the respondents were male (sex ratio: 0.587). The findings were consistent with the study done among tourist in air conditioned hotel lobbies in Thailand [19] and Turkey [20].

The tourists taken in the study were mainly European (65.8\%); these findings were similar to the study among tourists in Thailand as well but in contrast to the residence region where they were mainly Asians (41\%) and white people (38\%) Exactly half (50\%) of the respondents taken in the study were smokers, $40 \%$ non-smokers and $10 \%$ ex-smokers and were similar with one of the studies among tourists in Thailand in terms of ex-smokers and smokers but non-smokers were in majority (47.9\%). Also the findings were consistent with the study done in Turkey among workers.

The new information from the study is the number of visit made to Thailand, it was found that $45.1 \%$ of the respondents were on their first visit and $29 \%$ had already visited more than three times. Moreover, $65.8 \%$ indicated that they would visit Thailand again if a 100\% smoke-free regulation were in place, $23.2 \%$ were unsure and only $12.1 \%$ indicated that they would not visit Thailand. The findings were similar to the one done among tourists in Thailand.

\subsection{Awareness about the Smoke-Free Policy at the Airport}

The findings showed that only $26.5 \%$ of the respondents were aware of the smoke-free policy at the airport, i.e., $45 \%$ of smokers and $8 \%$ of non-smokers were aware of the smoke-free policy. Among 200 respondents 35\% knew about smoking being allowed at the airport, 25.6\% knew about the presence of DSRs at the airport, $27.4 \%$ knew about the fine for flouting the law. These findings were consistent with a study done in Morocco. When compared to the study done in Turkey, the findings from this study were very poor in terms of awareness [21]. 


\subsection{Perception of the Smoke-Free Policy}

The findings from the study had shown that $42 \%$ of the respondents had a good and $40.5 \%$ had a fair perception of the smoke-free policy at the airport. It was also found that current smoking status $(p \leq 0.001)$, awareness levels $(p \leq 0.001)$ and residence of the respondents $(p \leq 0.001)$ were related in a statistically significantly manner to the perception of the smoke-free policy. None of the previous studies had explored the perception. None of the studies among the tourists at the airport had been found to measure the perception of the smoke-free policy.

\subsection{Support for $100 \%$ Smoke-Free Policy}

The findings revealed that a majority (partial ban $51.8 \%$ and total ban $46.7 \%$ ) of the respondents supported a partial ban policy. The majority (58\%) of current smokers supported a $100 \%$ smoke-free policy. Similar results were found in a study of 19 states in America [22] and the UK [23]. But a study from Ghana contradicts the show of strong support (97\%) for comprehensive smoke-free legislation, particularly among Christians and Muslims [24]. Studies have revealed that once the comprehensive policy is implemented, within short time the support rises up significantly. From the study it was found that all the tourists from Argentina, Bangladesh, China, Estonia, Ireland, Malaysia, Maldives, Myanmar, New Zealand, Papua New Guinea, UAE and Vietnam had totally supported the smoke-free policy whereas the majority of the tourists from Australia, Denmark, England, Nepal and Sweden had supported it, butonly $50 \%$ of the tourists from USA, Switzerland, Bahrain, Brazil, Israel and Netherland and among the tourists from rest of the countries (out of 43 countries) either a minority or no support at all for the smoke-free policy was found. Results reflected that awareness and perception of the smoke-free policy are significantly associated and the respondent's residence as well as perception had a predictive relationship with the support for a smoke-free policy.

\section{Conclusions}

Based on the responses obtained from 200 departing tourists on the 4th floor of Suvarnabhumi International Airport, a smoke-free policy is well supported and needs strict enforcement so as to improve awareness among them and enhance the perception towards the smoke-free policy at the airport. It was found that around $75 \%$ of respondents were unaware of the smoke-free policy at the airport and two-third of respondents would like to come to Thailand even when it is $100 \%$ smoke-free. In the study association of general characteristics such as age, gender, educational status, marital status, smoking status, number of visit to Thailand, residence of the respondents, awareness on airport smoke-free policy, levels of knowledge with perception and support for $100 \%$ smoke-free policy were explored.

The results showed that two factors, current smoking status, and knowledge levels had a statistically significant association with perception. Likewise, three factors had significant association with the support for the $100 \%$ smoke-free policy. They are tourists' level of perception, region of respondent residence, and presence of Designated Smoking Rooms (DSRs). All other factors taken into account did not reveal any association with the perception and support for a smoke-free policy. 


\section{Recommendations}

The following recommendations are based on the research findings and aimed at organizations and other concerned authorities.

\subsection{At the Institutional Level}

1. Since the study findings revealed that almost three fourths of the respondents were unaware of the airport smoke-free policy, the airport authority needs an effective display of the no smoking warning.

2. It has also been found that some of the respondents smoke in the toilet and rest rooms which is against the policy, so to minimize risk from such acts, airport authorities at least can have information on the presence of Designated Smoking Rooms inside the airport.

3. Haphazard smoking allowed outside the building at the airport keeps at stake the health of all, so it needs proper management and an effective monitoring system is the need at the airport in order to move towards a $100 \%$ smoke-free environment.

\subsection{Policy Level}

4. Almost all of the respondents were of the view that airport should be smoke-free; this needs to be taken into account by policy makers.

5. For effectively communicating the smoke-free policy among the public regardless of the nationality to raise the awareness and ultimately protect the people, there is a need for a strong education, advocacy and enforcement programme with a monitoring system in place.

6. Perception of the smoke-free policy can help in explaining the support for the law, so there is need for further research in the area among both patrons and the workers at the airport which could clearly come up the support for a $100 \%$ smoke-free airport. This would help in establishing an effective comprehensive policy in the airport and ultimately ensure the right to breathe toxin-free air.

\section{Acknowledgments}

Funding for this research project was supported by China Medical Board (CMB), Faculty of Public Health, Mahidol University; and by the Tobacco Control and Knowledge Management Research Center (TRC), Mahidol University.

\section{Conflicts of Interest}

The authors declare no conflict of interest.

\section{References}

1. Report on carcinogens. US Department of Health and Human Services, Public Health Service, National Toxicology Program. 2011. Available online: http://ntp.niehs.nih.gov/ntp/roc/twelfth/ roc12.pdf (accessed on 5 April 2012). 
2. Oberg, M.; Jaakkola, M.S.; Woodward, A.; Peruga, A.; Pruss-Ustun, A. Worldwide burden of disease from exposure to second-hand smoke: A retrospective analysis of data from 192 countries. Lancet 2010, 377, 143, doi: 10.1016/S0140-6736 (10) 61388-8.

3. The Health Consequences of Involuntary Exposure to Tobacco Smoke: A Report of the Surgeon General; Office on Smoking and Health, Centers for Disease Control and Prevention: Atlanta, GA, USA, 2006; p. 727.

4. Who Report on the Global Tobacco Epidemic, 2011: Warning about the Dangers of Tobacco; World Health Organization: Geneva, Switzerland, 2011; p. 152.

5. Scollo, M.; Lal, A.; Hyland, A.; Glantz, S. Review of the quality of studies on the economic effects of smoke-free policies on the hospitality industry. Tob. Control 2003, 12, 7, doi: 10.1136/tc.12.1.13.

6. Griffith, G. Global Smokefree Partnership (2010) Article 8 Status Report. Global Smokefree Partnership: 2010. Available online: http://www.globalsmokefree.com/gsp/resources/ficheiros/ statusreportonarticle8/pdf (accessed on 29 April 2012).

7. Hammond, D.; Kin, F.; Prohmmo, A.; Kungskulniti, N.; Lian, T.Y.; Sharma, S.K.; Sirirassamee, B.; Borland, R.; Fong, G.T. Patterns of smoking among adolescents in malaysia and thailand: Findings from the international tobacco control southeast asia survey. Asia Pac. J. Public Health 2008, 20, 11, doi: 10.1177/1010539508317572.

8. China Health Communications Campaigns. Available online: http://www.worldlungfoundation.org /ht/D/sp/i/7217/pid/7217 (accessed on 5 April 2012).

9. Villarreiz, D.C. Framework Convention on Tobacco Control. Article 8: Protection from Exposure to Tobacco Smoke. Smoke-Free Policies and Enforcement in the Asean. Southeast Asia Tobacco Control Alliance (SEATCA). 2010. Available online: http://seatca.org/dmdocuments/smokefree\% 20policies\%20and\%20enforcement\%20in\%20the\%20asean.pdf (accessed on 15 April 2012).

10. Wan, M.P.; Wu, C.L.; Chan, T.T.; Chao, C.Y.; Yeung, L.L. Removal and leakage of environmental tobacco smoke from a model smoking room. J. Occup. Environ. Hyg. 2010, 7, 13, doi: 10.1080/15459624.2010.504432.

11. Erazo, M.; Iglesias, V.; Droppelmann, A.; Acuna, M.; Peruga, A.; Breysse, P.N.; Navas-Acien, A. Secondhand tobacco smoke in bars and restaurants in santiago, chile: Evaluation of partial smoking ban legislation in public places. Tob. Control 2010, 19, 6, doi: 10.1136/tc.2009.035402.

12. Singer, B.C.; Hodgson, A.T.; Guevarra, K.S.; Hawley, E.L.; Nazaroff, W.W. Gas-phase organics in environmental tobacco smoke. 1. Effects of smoking rate, ventilation, and furnishing level on emission factor. Environ. Sci. Technol. 2002, 36, 8. Available online: http://www.ncbi.nlm.nih.gov/pubmed/11918006 (accessed on 5 April 2012).

13. Lee, K.; Hahn, E.J.; Robertson, H.E.; Whitten, L.; Jones, L.K.; Zahn, B. Air quality in and around airport enclosed smoking rooms. Nicotine Tob. Res. 2010, 12, 4. Available online: http://www.ncbi.nlm.hih.gov/pubmed/20410143http://www.ncbi.nlm.hih.gov/pubmed/20410143 (accessed on 5 April 2012).

14. Indoor Air Quality. US Department of Labor: 04/05/1994. 1994. Available online: http://www.osha.gov/pls/oshaweb/owadisp.show_document?p_table=federal_register\&p_id=13369 (accessed on 5 April 2012). 
15. Smoking Restrictions in U.S. Large-Hub Airports-United States, 2002 and 2010. US Center for Disease Control and Prevention. 2010. Available online: http://www.cdc.gov/mmwr/preview/ mmwrhtml/mm5945a3.htmhttp://www.cdc.gov/mmwr/preview/mmwrhtml/mm5945a3.htm (accessed on 5 April 2012).

16. Environmental Tobacco Smoke: A Toxic Air Contaminant; California Environmental Protection Agency. 2006. Available online: http://www.arb.ca.gov/toxics/ets/factsheets.pdf (accessed on 15 April 2012).

17. Pion, M.; Givel, M.S. Airport smoking rooms don't work. Tob. Control 2004, 13, i37-i40.

18. California's Smoke-Free Workplace Act: Ending Exemptions-Finding Equity. 2011. Available online: http://www.cdph.ca.gov/programs/tobacco/Documents/CTCP-Theresa-Boschert.pdf (accessed on 15 April 2012).

19. Viriyachaiyo, V.; Lim, A. Tourists' attitudes towards ban on smoking in air-conditioned hotel lobbies in thailand. Tob. Control 2009, 18, 238-240.

20. Doruk, S.; Celik, D.; Etikan, I.; Inonil, H.; Yilmaz, A.; Seyfikli, Z.; Evaluation of the knowledge and manner of workers of workplaces in tokat about the ban on restriction of indoor smoking. Tuberg Toraks 2010, 58, 286-292.

21. Tachfouti, N.; El Rhazi, K.; Berraho, M.; Benjelloun, M.C.; Slama, K.; Nejjari, C. Knowledge and attitude about anti-smoking legislation in morocco according to smoking status. East. Mediterr. Health J. 2011, 17, 297-302.

22. McClave, A.K.; Whitney, N.; Thorne, S.L.; Mariolis, P.; Dube, S.R.; Engstrom, M. Adult tobacco survey - 19 states, 2003-2007. MMWR Surveill. Summ. 2010, 59, 1-75.

23. Rayens, M.K.; Hahn, E.J.; Langley, R.E.; Hedgecock, S.; Butler, K.M.; Greathouse-Maggio, L. Public opinion and smoke-free laws. Policy Polit. Nurs. Pract. 2007, 8, 262-270.

24. Owusu-Dabo, E.; Lewis, S.; McNeill, A.; Gilmore, A.; Britton, J. Support for smoke-free policy, and awareness of tobacco health effects and use of smoking cessation therapy in a developing country. BMC Public Health 2011, 11, 572, doi: 10.1186/1471-2458-11-572. 


\section{Appendix}

Table A1. Case Processing Summary.

\begin{tabular}{|c|c|c|c|}
\hline \multicolumn{2}{|l|}{ Variables } & \multirow{2}{*}{$\begin{array}{l}n \\
86\end{array}$} & \multirow{2}{*}{$\begin{array}{c}\text { Marginal Percentage } \\
46.0 \%\end{array}$} \\
\hline Support $100 \%$ smoke free policy & Yes & & \\
\hline & No & 101 & $54.0 \%$ \\
\hline \multirow[t]{3}{*}{ Categories of knowledge (level) } & Poor & 143 & $76.5 \%$ \\
\hline & Average & 26 & $13.9 \%$ \\
\hline & Good & 18 & $9.6 \%$ \\
\hline \multirow[t]{2}{*}{ Age grouped into two categories } & 18-35 YEARS & 107 & $57.2 \%$ \\
\hline & Above 35 years & 80 & $42.8 \%$ \\
\hline \multirow[t]{3}{*}{ Categories of perception (Levels) } & poor & 33 & $17.6 \%$ \\
\hline & Average & 75 & $40.1 \%$ \\
\hline & Good & 79 & $42.2 \%$ \\
\hline \multirow[t]{7}{*}{ Grouped countries according to $\mathrm{WHO}$} & Africa & 4 & $2.1 \%$ \\
\hline & The Americas & 20 & $10.7 \%$ \\
\hline & South-East Asia & 13 & $7.0 \%$ \\
\hline & Europe & 123 & $65.8 \%$ \\
\hline & Eastern & 8 & $4.3 \%$ \\
\hline & Mediterranean & & \\
\hline & Western Pacific & 19 & $10.2 \%$ \\
\hline \multirow[t]{3}{*}{ Come_again } & Yes & 125 & $66.8 \%$ \\
\hline & might & 40 & $21.4 \%$ \\
\hline & No & 22 & $11.8 \%$ \\
\hline \multirow[t]{2}{*}{ Awareness } & Yes & 64 & $34.2 \%$ \\
\hline & no & 123 & $65.8 \%$ \\
\hline \multirow[t]{2}{*}{ Fine for violating } & yes & 64 & $34.2 \%$ \\
\hline & no & 123 & $65.8 \%$ \\
\hline \multirow[t]{2}{*}{ DSRs presence } & yes & 48 & $25.7 \%$ \\
\hline & no & 139 & $74.3 \%$ \\
\hline Valid & & 187 & $100.0 \%$ \\
\hline Missing & & 13 & \\
\hline Total & & 200 & \\
\hline Subpopulation & & $142^{\mathrm{a}}$ & \\
\hline
\end{tabular}

${ }^{a}$ The dependent variable has only one value observed in 128 (90.1\%) subpopulations.

Table A2. Model Fitting Information.

\begin{tabular}{ccccc}
\hline & Model Fitting Criteria & \multicolumn{3}{c}{ Likelihood Ratio Tests } \\
\cline { 2 - 5 } Model & $\mathbf{- 2}$ Log Likelihood & Chi-Square & df & Sig. \\
\hline Intercept Only & 228.270 & & & \\
\hline Final & 137.025 & 91.245 & 17 & 0.000 \\
\hline
\end{tabular}


Table A3. Pseudo R-Square.

\begin{tabular}{cc}
\hline Cox and Snell & 0.386 \\
Nagelkerke & 0.516 \\
McFadden & 0.354 \\
\hline
\end{tabular}

Table A4. Parameter Estimates.

\begin{tabular}{|c|c|c|c|c|c|c|c|c|}
\hline \multirow{2}{*}{$\begin{array}{c}\begin{array}{c}\text { Support } 100 \% \text { smoke } \\
\text { free policy }^{\text {a }}\end{array} \\
\text { Intercept }\end{array}$} & \multirow[t]{2}{*}{ B } & \multirow[t]{2}{*}{$\begin{array}{l}\text { Std. } \\
\text { Error }\end{array}$} & \multirow[t]{2}{*}{ Wald } & \multirow[t]{2}{*}{ df } & \multirow[t]{2}{*}{ Sig. } & \multirow[t]{2}{*}{$\operatorname{Exp}(B)$} & \multicolumn{2}{|c|}{$\begin{array}{c}\text { 95\% Confidence Interval for } \\
\operatorname{Exp(B)} \\
\end{array}$} \\
\hline & & & & & & & Lower Bound & Upper Bound \\
\hline SEX & -0.162 & 0.449 & 0.131 & 1 & 0.718 & 0.850 & & 2.051 \\
\hline MRTL_STAT & 0.422 & 0.370 & 1.303 & 1 & 0.254 & 1.526 & 0.739 & 3.151 \\
\hline$[$ Knowledge_level $=1]$ & -1.065 & 1.524 & 0.488 & 1 & 0.485 & 0.345 & 0.017 & 6.839 \\
\hline$[$ Knowledge_level $=2]$ & -1.111 & 1.337 & 0.690 & 1 & 0.406 & 0.329 & 0.024 & 4.524 \\
\hline$[$ Knowledge_level = 3] & $0^{\mathrm{b}}$ & & & 0 & & & & \\
\hline [Age_group = 1] & 0.546 & 0.418 & 1.704 & 1 & 0.192 & 1.726 & 0.761 & 3.914 \\
\hline [Age_group = 2] & $0^{\mathrm{b}}$ & & & 0 & & & & \\
\hline$[$ Level_Perception $=1]$ & 2.590 & 0.849 & 9.298 & 1 & 0.002 & 13.324 & 2.522 & 70.389 \\
\hline$[$ Level_Perception $=2]$ & 1.349 & 0.446 & 9.153 & 1 & 0.002 & 3.854 & 1.608 & 9.234 \\
\hline [Level_Perception = 3] & $0^{\mathrm{b}}$ & & & 0 & & & & \\
\hline [Country_Group=1] & 2.224 & 1.474 & 2.276 & 1 & 0.131 & 9.247 & 0.514 & 166.315 \\
\hline [Country_Group = 2] & 2.120 & 0.902 & 5.530 & 1 & 0.019 & 8.334 & 1.424 & 48.784 \\
\hline [Country_Group = 3] & -0.912 & 1.181 & 0.597 & 1 & 0.440 & 0.402 & 0.040 & 4.064 \\
\hline [Country_Group=4] & 2.017 & 0.760 & 7.040 & 1 & 0.008 & 7.514 & 1.694 & 33.329 \\
\hline [Country_Group = 5] & 0.774 & 1.199 & 0.417 & 1 & 0.518 & 2.169 & 0.207 & 22.744 \\
\hline [Country_Group=6] & $0^{\mathrm{b}}$ & & & 0 & & & & \\
\hline$[$ co_again $=1.00]$ & -1.402 & 0.915 & 2.349 & 1 & 0.125 & 0.246 & 0.041 & 1.478 \\
\hline$[$ co_again $=2.00]$ & -0.440 & 0.972 & 0.205 & 1 & 0.650 & 0.644 & 0.096 & 4.323 \\
\hline$[$ co_again $=3.00]$ & $0^{\mathrm{b}}$ & & & 0 & & & & \\
\hline$[$ aware $=1.00]$ & -0.751 & 0.659 & 1.297 & 1 & 0.255 & 0.472 & 0.130 & 1.718 \\
\hline$[$ aware $=2.00]$ & $0^{\mathrm{b}}$ & & & 0 & & & & \\
\hline$[$ FineV $=1.00]$ & 0.482 & 0.493 & 0.954 & 1 & 0.329 & 1.619 & 0.616 & 4.254 \\
\hline$[$ FineV $=2.00]$ & $0^{\mathrm{b}}$ & & & 0 & & & & \\
\hline$\left[\mathrm{DSR} \_\mathrm{s}=0\right]$ & -1.369 & 0.707 & 3.753 & 1 & 0.043 & 0.254 & 0.064 & 1.016 \\
\hline$\left[\mathrm{DSR} \_\mathrm{s}=1\right]$ & $0^{\mathrm{b}}$ & & & 0 & & & & \\
\hline
\end{tabular}

${ }^{a}$ The reference category is: Yes; ${ }^{b}$ This parameter is set to zero because it is redundant.

(C) 2013 by the authors; licensee MDPI, Basel, Switzerland. This article is an open access article distributed under the terms and conditions of the Creative Commons Attribution license (http://creativecommons.org/licenses/by/3.0/). 